\title{
Hydroa Vacciniforme-Like Lymphoproliferative Disorder in an Adult Patient With Chronic Lymphocytic Leukemia
}

\author{
Ashlyn Chee ${ }^{\mathrm{a}, \mathrm{e}}$, Benjamin Wood ${ }^{\mathrm{b}}$, Genevieve Sadler $^{\mathrm{c}}$, Gavin Cull ${ }^{\mathrm{a}, \mathrm{d}}$
}

\begin{abstract}
Hydroa vacciniforme-like lymphoproliferative disorder (HV-LPD) is a rare Epstein-Barr virus (EBV)-positive T-cell lymphoproliferative disorder (LPD) which primarily affects children from Latin America and Asia. Typical features include vesicles and ulceration in sun-exposed areas which may be accompanied by systemic symptoms such as fever, lymphadenopathy and hepatosplenomegaly. We report a 73-year-old man diagnosed with HV-LPD in the context of zanubrutinib (oral Bruton tyrosine kinase (BTK)-inhibitor) treatment for chronic lymphocytic leukemia (CLL). The patient presented with slowly progressive peri-orbital edema and erythema non-responsive to topical therapies which eventually progressed to focal crusting and erosion. Prednisolone was subsequently introduced, which led to a good response in the patient's symptoms.
\end{abstract}

Keywords: Lymphoproliferative disorder; EBV; CLL

\section{Introduction}

Hydroa vacciniforme-like lymphoproliferative disorder (HVLPD) is an Epstein-Barr virus (EBV) driven disorder mainly affecting $\mathrm{T}$ cells, with up to one-third having a natural killer (NK) cell origin [1]. It is broadly classified into the classic and systemic forms and they likely represent the same disease process on a continuum of EBV-associated cutaneous lymphoproliferative disorders (LPDs) but with different clin-

Manuscript submitted September 1, 2020, accepted September 8, 2020

Published online September 23, 2020

a Department of Haematology, Sir Charles Gairdner Hospital, Hospital Ave, Nedlands, Western Australia 6009, Australia

bDepartment of Anatomical Pathology, Sir Charles Gairdner Hospital, Hospital Ave, Nedlands, Western Australia 6009, Australia

'Department of Dermatology, Sir Charles Gairdner Hospital, Hospital Ave, Nedlands, Western Australia 6009, Australia

dUniversity of Western Australia School of Medicine, Crawley, Western Australia 6009, Australia

${ }^{e}$ Corresponding Author: Ashlyn Chee, Department of Haematology, Sir Charles Gairdner Hospital, Hospital Ave, Nedlands, Western Australia 6009, Australia.Email: ashchee@hotmail.com

doi: https://doi.org/10.14740/jmc3576 ical severities [1-3].

Classic HV-LPD was originally described in the Caucasian population and is characterized by a photodermatosis originating as vesicles, evolving to crusts and leaving varicelliform scars after healing [1-4]. Systemic symptoms are usually not observed and this benign condition normally improves with sun avoidance and resolves spontaneously in adolescence [1-4].

Systemic hydroa vacciniforme (HV) typically affects children and adolescents from Asia and Latin America [1-4]. This generally presents as a more severe cutaneous condition; however, systemic features including constitutional symptoms, hepatosplenomegaly and lymphadenopathy are also present. T-cell clonality and a high EBV viral load in the blood are usually detected [3]. Around 20-50\% of those diagnosed with systemic HV have a relapsing and remitting course eventually progressing to an EBV positive NK/T-cell lymphoma over 10 -15 years which may be fatal $[2,3,5,6]$. No prognostic variables have been determined [2]. First-line treatment is generally with immunomodulating therapies $[2,3]$.

Adult cases of HV-LPD in the Caucasian population have rarely been reported $[7,8]$. The clinical features of HV-LPD in adults are similar to children, although facial swelling and oral ulceration have been described [7]. A case series of children from Bolivia who presented with predominantly periorbital swelling has also been reported [9].

\section{Case Report}

We describe a case of HV-LPD involving the face in a 73-yearold man being treated for chronic lymphocytic leukemia (CLL) with zanubrutinib (a Bruton tyrosine kinase (BTK)inhibitor). He was diagnosed with early-stage CLL with a 13q deletion in 2006. He was treated for progressive CLL in 2010 with six cycles of fludarabine, cyclophosphamide and rituximab (FCR). He achieved a complete remission but had progressive CLL in 2013 and was re-treated with a further six cycles of FCR. In 2014 he again had progressive CLL and was treated on a clinical trial of bendamustine-rituximab (BR) +/- idelalisib/placebo (drew placebo). He received six cycles of BR and achieved a partial remission. In 2016, he was commenced on treatment with zanubrutinib, a highly selective BTK inhibitor, in a clinical trial [10]. He responded well with normalization of lymphocyte count, improvement in hematological parameters and resolution of lymphadenop- 

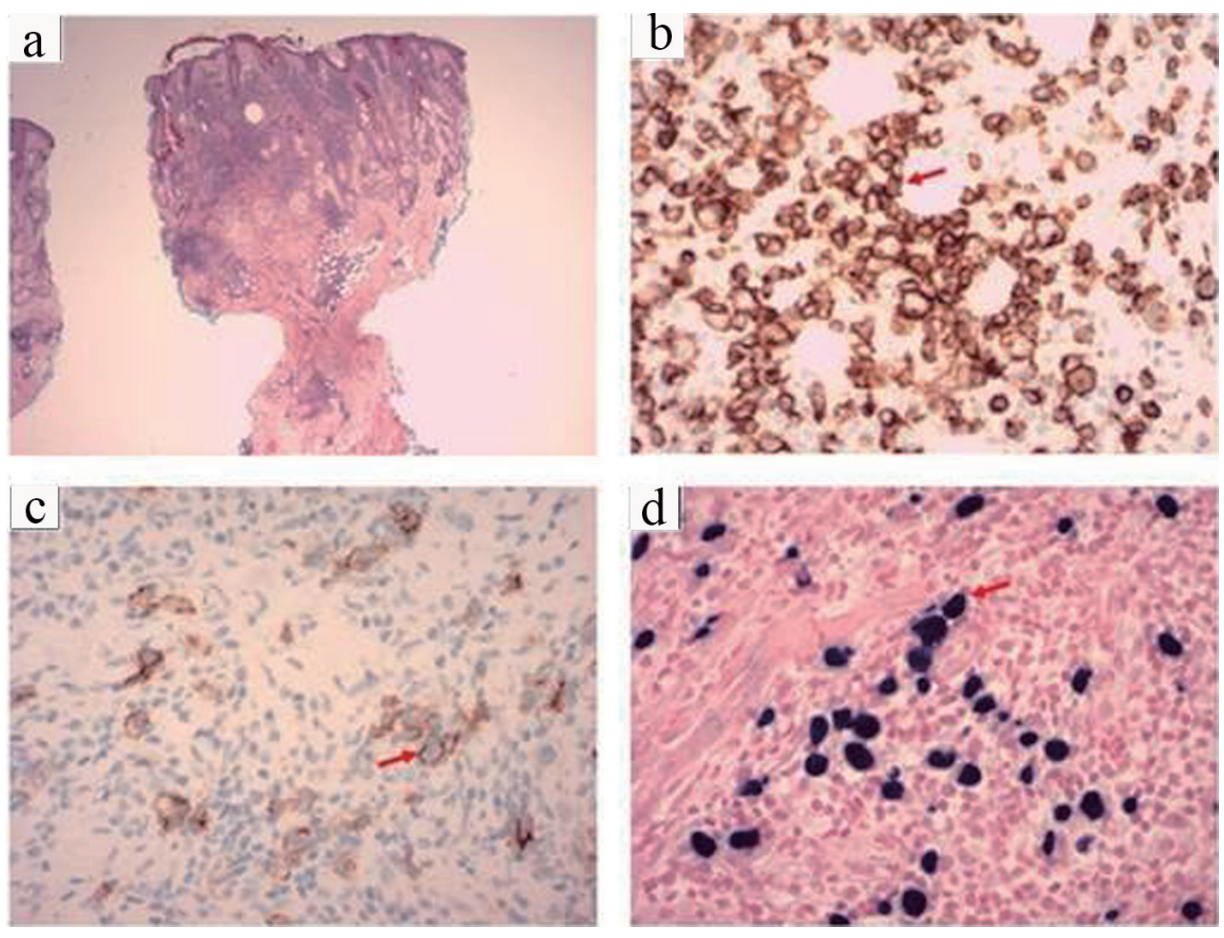

Figure 1. (a) Hematoxylin and eosin (H\&E) $(\times 20)$ stain of the coronal section of the skin biopsy showing parakeratosis, surface inflammatory scale crust and dense lymphoid infiltrate. (b) CD2 (× 400) positive staining highlighting T cells in brown (arrow). (c) CD56 ( $\times 400)$ positive in large cells staining brown (arrow). (d) Epstein-Barr virus-encoded small RNAs $($ EBER) $(\times 400)$ positive in large cells staining dark blue (arrow).

athy and splenomegaly.

He first noticed mild peri-orbital edema in July 2018 and was reviewed by an ophthalmologist and treated with topical and oral antibiotics without benefit. A magnetic resonance imaging (MRI) of the orbit excluded any masses or obstruction. Subsequently, he stopped zanubrutinib in September 2018 for 4 weeks to undergo a Whipple's procedure for an intraductal papillary mucinous neoplasm but the peri-orbital edema remained unchanged. In November 2019 the peri-orbital edema increased and focal crusted plaques and erosions developed. He was reviewed by a dermatologist and treated with topical steroids and tacrolimus ointment without benefit. Antinuclear antibody (ANA), creatine kinase (CK) and patch testing for suspected allergic contact dermatitis were negative.

In January 2020 biopsies were obtained from the left suprabrow, right infraorbital, left pre-auricular and left postauricular regions. The biopsies showed areas of parakeratosis and surface inflammatory scale crust, follicular plugging with demodex mites and focal suppurative infundibular folliculitis and a dense superficial and deep perivascular and periadnexal infiltrate. In addition to small and medium sized lymphocytes, histiocytes and eosinophils, the dermal infiltrate included a population of larger lymphoid cells with nuclear hyperchromasia and pleomorphism. Immunohistochemistry showed these large cells to be positive for $\mathrm{CD} 2, \mathrm{CD} 3, \mathrm{CD} 30$ and CD56 (Fig. 1). These cells were uniformly positive for EBV early RNA by in situ hybridization, with smaller numbers of cells showing latent membrane protein 1 (LMP1) staining, but no staining for Epstein-Barr virus nuclear antigen 2 (EBNA2), consistent with EBV latency pattern II (Fig. 1). T-cell receptor $(T C R)$ gene rearrangement studies on the tissue revealed monoclonal $T C R$ beta and TCR gamma gene rearrangements.

A positron emission tomography (PET) scan revealed mild left para-aortic lymphadenopathy and splenomegaly of $18 \mathrm{~cm}$, both with low-grade fluorodeoxyglucose (FDG) avidity and consistent with CLL. Bone marrow biopsy revealed low level involvement with CLL and no morphological or immunophenotypic features for an aberrant T-cell population. EBV was detected in the plasma at a low level of $1.39 \times 10^{2} \mathrm{IU} / \mathrm{mL}$. $T C R$ gene rearrangement studies of peripheral blood revealed polyconal products.

Initial treatment consisted of cessation of zanubrutinib, treatment of demodex mites with ivermectin and strict avoidance of sun exposure. There was no significant improvement and he was commenced on hydroxychloroquine $400 \mathrm{mg}$ nocte. After 2 weeks of therapy there was further progression of the facial edema and ulceration and hydroxychloroquine was changed to prednisolone $1 \mathrm{mg} / \mathrm{kg}$. This resulted in rapid improvement with virtual complete resolution of facial edema. Upon steroid weaning, there has been a mild recurrence of facial edema in a focal distribution and the patient remained on prednisolone $10 \mathrm{mg}$ per day.

Concurrent with the diagnosis of HV-LPD, there was progressive deterioration in liver function which had been mildly abnormal since the Whipple's procedure. Concern the patient may be developing a T-cell LPD in the liver led to a liver bi- 
opsy which revealed most portal tracts were infiltrated with CLL. There was no evidence of large cell transformation or HV-LPD. The patient has since been commenced on venetoclax.

\section{Discussion}

Richter's transformation to a high-grade B-cell lymphoma occurs in around $5 \%$ of patients with CLL [11]; however, an NK or T-cell neoplasm arising in pre-existing CLL is unusual [1214]. Reports of anaplastic large cell lymphoma (ALCL) and peripheral T-cell lymphoma (PTCL) in CLL have been limited to case series [15]. However, a large Surveillance, Epidemiology and End Results (SEER) study has shown that male patients with CLL were found to have an increased risk of developing cutaneous T-cell lymphoma (CTCL) compared to the general population, with an incidence of 104.2 per 1,000,000 personyears [16]. The association between CLL and T-cell LPDs is not clearly defined although it has been hypothesized that reduced immune surveillance, defective $\mathrm{T}$ cell function from chronic stimulation of cytotoxic $\mathrm{T}$ cells [12-15] or malignant transformation originating from a common stem cell progenitor $[15,16]$ could play a role. No direct relationship with previous CLL treatments or EBV infection has been established [14].

BTK-inhibitors are now standard of care for many patients with CLL and demonstrate improved outcomes compared with chemo-immunotherapy. Zanubrutinib is a potent and selective BTK-inhibitor which has shown to be safe and effective in CLL [10]. Long-term follow-up of ibrutinib, the first in class BTK-inhibitor, in previously treated CLL patients has not found significant safety signals regarding infection [17]. While concerns over invasive fungal infection have been raised and vigilance is required [18], the incidence is relatively low [17, 19]. Of note, disseminated viral infections such as EBV do not appear to be an issue [17-20]. Our patient had previously received treatment with FCR and BR and it can be postulated that the associated immunosuppression may be a risk factor for the EBV viremia and HV-LPD.

The best treatment approach for HV-LPD is not known and indolent cases are usually treated conservatively [2, 7]. Immunomodulating therapies including prednisolone, cyclosporine, interferon alpha, chloroquine and thalidomide have been shown to induce remission and improvement in symptoms but an allogeneic stem cell transplant remains the only curative option in advanced cases [3]. Due to the potential risk of HV-LPD transforming to a systemic lymphoma it is important to continue to follow up these patients on a regular basis.

\section{Conclusions}

To our knowledge, this is the first case of HV-LPD occurring in an adult patient with CLL. The relationship between the HVLPD and CLL is uncertain, though it can be postulated that immunosuppression from prior therapy was a risk factor. Patients with CLL presenting with cutaneous lesions, particularly those with unusual clinical features, should undergo a thorough assessment including biopsy with adequate samples for morphological, immunophenotypic and molecular studies.

\section{Acknowledgments}

None to declare.

\section{Financial Disclosure}

None to declare.

\section{Conflict of Interest}

None to declare.

\section{Informed Consent}

Patient's informed consent for publication of this report was obtained.

\section{Author Contributions}

$\mathrm{AC}$ and $\mathrm{GC}$ were involved in the treatment of the patient and co-wrote the manuscript. GC was the primary hematologist for the patient. BW made the histological diagnosis and edited the manuscript. GS was consulted from the dermatology point of view and edited the manuscript.

\section{Data Availability}

The authors declare that data supporting the findings of this study are available within the article.

\section{References}

1. Quintanilla-Martinez L, Ko YH, Kimura H, et al. EBVpositive T-cell and NK-cell lymphoproliferative disorders of childhood. In: Swerdlow S, Campo E, Harris N, et al ed. Lyon; IARC; 2017:360-362.

2. Quintanilla-Martinez L, Ridaura C, Nagl F, Saez-de-Ocariz M, Duran-McKinster C, Ruiz-Maldonado R, Alderete $\mathrm{G}$, et al. Hydroa vacciniforme-like lymphoma: a chronic $\mathrm{EBV}+$ lymphoproliferative disorder with risk to develop a systemic lymphoma. Blood. 2013;122(18):3101-3110.

3. Quintanilla-Martinez L, Fend F. Deciphering hydroa vacciniforme. Blood. 2019;133(26):2735-2737.

4. Cohen JI, Manoli I, Dowdell K, Krogmann TA, Tamura $\mathrm{D}$, Radecki P, Bu W, et al. Hydroa vacciniforme-like lymphoproliferative disorder: an EBV disease with a low risk of systemic illness in whites. Blood. 2019;133(26):2753- 
2764.

5. Yang YQ, Fan L, Wang L, Xu J, Zhang R, Ge Z, Li JY, et al. Systemic lymphoma arising from hydroa vacciniforme-like lymphoma: report of two cases with review of literature. Int J Clin Exp Pathol. 2014;7(9):6403-6408.

6. Chen CC, Chang KC, Medeiros LJ, Lee JY. Hydroa vacciniforme and hydroa vacciniforme-like T-cell lymphoma: an uncommon event for transformation. J Cutan Pathol. 2016;43(12):1102-1111.

7. Wen PF, Liu H. Hydroa vacciniforme-like cutaneous T-cell lymphoma in an adult presenting with facial edema and recurrent oral ulceration. Am J Dermatopathol. 2018;40(3):227-229.

8. Nomura H, Suzuki H, Egami S, Yokoyama T, Sugiura M, Tomita K, Imada M, et al. A patient with elderly-onset atypical hydroa vacciniforme with an indolent clinical course. Br J Dermatol. 2015;173(3):801-805.

9. Plaza JA, Sangueza M. Hydroa vacciniforme-like lymphoma with primarily periorbital swelling: 7 cases of an atypical clinical manifestation of this rare cutaneous Tcell lymphoma. Am J Dermatopathol. 2015;37(1):20-25.

10. Tam CS, Trotman J, Opat S, Burger JA, Cull G, Gottlieb D, Harrup R, et al. Phase 1 study of the selective BTK inhibitor zanubrutinib in B-cell malignancies and safety and efficacy evaluation in CLL. Blood. 2019;134(11):851859.

11. Tsimberidou AM, Wen S, McLaughlin P, O'Brien S, Wierda WG, Lerner S, Strom S, et al. Other malignancies in chronic lymphocytic leukemia/small lymphocytic lymphoma. J Clin Oncol. 2009;27(6):904-910.

12. Boyer DF, Lindeman NI, Harris NL, Ferry JA. Peripheral T-cell lymphomas with cytotoxic phenotype in patients with chronic lymphocytic leukemia/small lymphocytic lymphoma. Am J Surg Pathol. 2014;38(2):279-288.

13. Mant S, Taylor G, Dutton D, Butler A, Browett P, Ganly P. Development of T-cell lymphomas with an activated cytotoxic immunophenotype, including anaplastic large cell lymphomas, in patients with chronic lymphocytic leukemia: a series of six cases. Leuk Lymphoma. 2015;56(3):774-778.

14. Martinez A, Pittaluga S, Villamor N, Colomer D, Rozman M, Raffeld M, Montserrat E, et al. Clonal T-cell populations and increased risk for cytotoxic T-cell lymphomas in B-CLL patients: clinicopathologic observations and molecular analysis. Am J Surg Pathol. 2004;28(7):849858.

15. Van Der Nest B.M, Leslie C, Joske D, et al. Peripheral T-cell lymphoma arising in patients with chronic lymphocytic leukaemia. American Journal of clinical Pathology. 2019;20:1-10.

16. Chang TW, Weaver AL, Shanafelt TD, Habermann TM, Wriston CC, Cerhan JR, Call TG, et al. Risk of cutaneous T-cell lymphoma in patients with chronic lymphocytic leukemia and other subtypes of non-Hodgkin lymphoma. Int J Dermatol. 2017;56(11):1125-1129.

17. Munir T, Brown JR, O'Brien S, Barrientos JC, Barr PM, Reddy NM, Coutre S, et al. Final analysis from RESONATE: Up to six years of follow-up on ibrutinib in patients with previously treated chronic lymphocytic leukemia or small lymphocytic lymphoma. Am J Hematol. 2019;94(12):1353-1363.

18. Ghez D, Calleja A, Protin C, Baron M, Ledoux MP, Damaj G, Dupont M, et al. Early-onset invasive aspergillosis and other fungal infections in patients treated with ibrutinib. Blood. 2018;131(17):1955-1959.

19. Rogers KA, Mousa L, Zhao Q, Bhat SA, Byrd JC, El Boghdadly Z, Guerrero T, et al. Incidence of opportunistic infections during ibrutinib treatment for B-cell malignancies. Leukemia. 2019;33(10):2527-2530.

20. Tillman BF, Pauff JM, Satyanarayana G, Talbott M, Warner JL. Systematic review of infectious events with the Bruton tyrosine kinase inhibitor ibrutinib in the treatment of hematologic malignancies. Eur J Haematol. 2018;100(4):325-334. 